\title{
Empirical Evidence of Organizational Strategy and the Performance of Faith-Based Organizations
}

\author{
Fred Peter, Landmark University, Nigeria \\ Emmanue Adeiemi, Landmark University, Nigeria \\ Joy Ajibade, Landmark University, Nigeria \\ Adeshola Peter, Landmark University, Nigeria \\ Sunday Eze, Landmark University, Nigeria \\ Decster Lydia, Landmark University, Nigeria
}

Effective implementation of organisational strategy is considered a major tool for facilitating firm performance and global competitiveness. However, most academic discussions and debates in existing literature have limited the discourse of strategy implementation in profit-oriented organisations, particularly in the Nigerian context. Therefore, this study explored the impact of the constructs of organisational strategy and performance of a faith-based organisations. A survey of 297 respondants constitute the population for this study. The research study is descriptive in nature, and it adopted a mixed method research design. A simple regression analysis was utilized for the analysis of the completed questionnaire. Also, thematic analysis was used to analyse the qualitative interview. The result shows that personality of the employees significantly influences member satisfaction. Therefore, this study recommends that faith-based organisations must ensure that their organisations consistently provide training for employees in order accommodate people irrespective of their peculiarities.

\section{KEYWORDS}

Faith-Based Organisation, Religion, Social Support, Strategy

\section{INTRODUCTION}

Good strategy is an essential factor required to facilitate favourable business outcomes in today's highly competitive business environment. Hence, implementation of strategies that will help a business acquire competitive advantage is vital. As noted by Yanney, Dennis and Awuah, (2015) business strategy plays a major role in enhancing performance of businesses because it charts the future path that the business will navigate and determine how the business intends to get there. As such one can tie the performance of a firm to its business strategy and how well articulated the strategy is executed (Olson \& Bokor, 1995). Though the business environment is composed of various elements such as the existing internal and external culture, successful execution of strategy is a function of the dominant organisational culture. According to Baumgartner and Korhonen (2010), the implementation of strategies that create immense economic benefits for organisation requires that businesses put emphasis on service or product quality as a culture. 
Therefore, a major factor that drives the success of any organisation is the prevailing culture which is projected by performance and productivity of employees. Hence, culture is considered major when it comes to the subject of strategy (Hitt, Ireland, Sirmon \& Trahms, 2011). It needs to be emphasised that culture is affected by internal environments such as structures, processes, systems, leadership styles, internal decisions and external environment such as government regulations to mention a few. However, the major focus of this study shall be the internal environment. Every business has the liberty to articulate and design a structure that will empower its strategy and facilitate the attainment of organisational goals (Yanney, Dennis, \& Awuah, 2015). Faith based organisation is not an exception.

Although faith-based organisations in Nigeria have contributed immensely to the socio-economic development of the country, existing literature has paid little attention to their efforts in national development and in particular their strategy implementation and performance. It is in this light, that this study examined the extent to which the implementation of strategy impact on the performance of faith-based organisations.

The specific objectives Includes:

I. To examine the influence of mechanic (Ambiance) clues on loyalty

II. To assess the influence of organisational social support on satisfaction.

\section{Strategy Implementation}

The implementation of strategy is regarded as one the most difficult and time-consuming aspect of strategy management. This is premised on the fact that formulating a successful strategy does not translate into strategy implementation success. Preble (1992) opined that a huge portion of time of manager is allocated to implementation which requires programming, motivation and controlling.

Strategic management process encapsulates set of decisions, commitments, and actions necessary for a business to enjoy strategic competitiveness (Hitt et al., 2011; Sunday \& Vera, 2018).) with strategy implementation as a part of the entire process. Implementation of strategy, thus, involves being meticulous with processes and ensuring that strategies formulated within the firm are implemented to drive the attainment business objectives and goals (Mbithe, 2011). However, based on the unpredictability and nature of any venture challenges begin to emerge in the course of the implementation of strategy. It is important to note that such challenges can be categorise into two major components such as organisational impeders and environmental obstacles. Organisational impeders are concerned with leadership, policies, systems, resource and capabilities while environment problems involve those issues as regard political, economic, social, donor, and legal issues (Nour, 2013).

\section{Non-Governmental Organisations (NGO)}

Omar, Leach and March (2014) viewed NGOs as self-regulating, private, non proðt oriented organisations that are designated to enhance community's quality of life. The phrase "NGO" is often liked with organisation that engage in charity work in developing countries or across borders. It originated during the creation of the United Nations in 1945 to denote non-state entities operating as consultants in UN activities (Lewis, 2010). For many years, NGO's have function at local, national and international levels providing social and economic values. Researches indicated that as at today, a many more NGOs are participating in activities focus on religious; they provide social services on the platform of faith-based NGOs.

\section{Mechanic Clues}

The purpose of mechanic clues is to produce a practical, beautiful and efficient service environment. Haeckel et al. (2003) observed that mechanic clues originate from inanimate objects or environments and involve tangible evidence of the service. It is projected in things such as building design, equipment, sound, furnishings, displays, colours, smells, lighting and all other physical clues, hence 
communicating values to clients without words. Mechanic clues find expression in tangible objects or surroundings and composed of smell, sight, sound, texture, and taste.

An appropriate environment can serve as a source of motivation for the efficient use of space and create a specific ambiance (Greenland \& McGoldrick, 1994). The physical appearance a church particularly the layout and design can communicate feelings of peace. Mechanic clue represent a cardinal foundation of physical layout that facilitates the process of envisioning by members of what to expect in a church service. It can generate great and lasting impressions on the customer which will shape their expectations of the kind of service that will be provided. The way consumers perceive the quality of services is based on evaluation of the experience and anticipations of service fit (Berry et al., 2006). In buttressing this point, Sharma and Stafford (2000) affirmed that the perceptions of customer about physical layout of an organisation can inspire the kind of feeling towards the organisation. Bitner (1992) argues that services are provided in faith-based organisation are premised on interpersonal relationship, hence the physical layout must be designed in a manner that promotes close contact between the consumer and the service provider (that is the congregation and the church). Berry et al. (2006) affirmed that mechanic clues are critical for rendering services in which customers experience the facilities for a long-given period, examples include hotels, churches and airplanes.

\section{Religious Social Support}

Most faith-based organisations are actively involved in the delivery of social services. These social services cover many areas such as the spiritual advancement and development of faith among members (Weisbrod, 1998). The services provided is expressed in their partnering in broader development objectives in areas where there are deficiency of resources (Kline, 2010; Wills, 1998). Similarly, Lim \& Putnam (2010) stated that individuals who participate in social networks especially in a faithbased organisation enjoy benefits advantages. As noted by Nagel and Sgoutas-Emch, (2007), active members of religious services group tend to enjoy broader social networks and participate in direct support activities than those who do not attend often (George, Ellison, \& Larson, 2002; Ellison \& George, 1994). Social activities are prominent in this context because religious organisations majorly consist of a group of people who share similar interest, culture and values (Ellison \& George, 1994; Olokundun, Olaleke, Peter, Ibidunni, \& Amaihian, 2017). Recent reports have it that $55 \%$ of African Americans go to church at least once every week (Kramer, 2010).

Extant literature has defined perceived social support offered by clergy and congregational members as religious social support, church-based support, or spiritual support (Kim, 2017). Based on the objective of this study and based on study done by (Krause \& Hayward, 2012), the term "religious social support" is adopted to define emotional support offered and received by members of faith-based organisations.

\section{Historical Development of FBOs in Nigeria}

The evolution of FBOs in Nigeria has remained elusive. However, an attempt is made to highlight the historical progression of the development and establishment of FBOs in Nigeria. Historically, Churches were the major providers of human development services such as education, healthcare and other social services. This dates to $1842 \mathrm{AD}$ when Christianity arrived.

It is vital to state that during the pre-colonial times, before 1861 , literatures reviewed fail to provide insights as regard the existence of FBOs of African traditional religion (ATR), as ATR is known to have preceded Christianity in Nigeria. The Supreme Being and deities were worshipped, and sacrifices offered to them in the belief that these supernatural beings would give the worshippers wealth, happiness and protection, which constitute aspects of human need (Baiyeri, 2013). 


\section{Role of FBOs in Nigeria}

The activities of FBOs cuts across every aspect of life. They range from educational, spiritual, health to social development. Based on inventory taken of past and present times development projects justify this claim. The following according to Baiyeri (2013), are some of the roles of FBO in Nigeria.

a. Political Development: FBOs have played huge role in advancing the politics in Nigeria.

b. Economic Development: Some of the Economic development programme of many churchowned financial institutions in Nigeria include the CFMB micro finance bank owned by Living Faith Church, Catholic Diocese of Nsukka own by the Kenechukwu Micro Finance Bank. These banks offer loans of various form and offer technical service to their customers. Hence, this support enhances the performance of small and medium scale business activities and be globally competitive. The general outcome of their performance is captured in the creation of employment opportunities, wealth creation, cottage industries, farm projects and agro-allied industries.

c. Educational programmes: In terms of educational development, many FBOs in Nigeria have contributed significantly to curriculum reform, building of classroom blocks, skills upgrade for teachers, provision of instructional materials, provision of feeding and boarding system in schools and colleges, and provision of entrepreneurship skill acquisition.

d. Health Care: The delivery of quality healthcare remains a cardinal developmental programme of FBO in Nigeria. For example, the Living Faith Church has established a clinic that provides quality health care in the communities

e. Social Development: Furthermore, social development initiatives which include gender related challenges, reproductive and girl-child education, women empowerment has remained a priority developmental programmes of many FBOs in Nigeria. An example is El-Shaddai Widow's Outreach (ELWO) of Suleja, Niger State which targets the promotion of the rights of minorities and marginalized population, advocacy, mobilization and creating awareness on health such as HIV/AIDS, reproductive health, family planning and adolescent health.

\section{Techniques for Analyzing the Environment}

In addition to the different approaches to strategy as highlighted above, there are also several techniques that have been developed over the years to assist organisations in the development of strategy. Some better-known techniques include:

\section{Porter's Five Forces}

Porter's five forces frame work was established in 1979 by Michael E. Porter as a tool for assessing and evaluating the competitive strength and position of a business firm.

This model is premised on the fact that there are five forces which help to determine the competitiveness and attractiveness of a market. The framework attempts to show where dominant power exists in a business setting. This is critical particularly in appreciating where the competitive strength of a business firm lies, and the level of position of strength that the firm may aspire to reach.

Experts in strategy often adopt Porter's five forces framework to validate if new products or services are viable and profitable. Based on the understanding of where dominant power exist, the model may also be used to identify areas of strengths and weaknesses to improve and to avoid mistakes.

The five forces are shown in Table 1 and Figure 1.

\section{World Mission Agency Corporate Strategy}

The Board of believes that for continuous growth to be experienced the organisation will need to provide quality services and expand its social impact on members. Therefore, the growth strategy that has been adopted will need to be reviewed and improved upon to sustain and grow the membership base otherwise members will seek service elsewhere. 


\begin{tabular}{|l|l|l|}
\hline \multicolumn{1}{|c|}{ S/N } & \multicolumn{1}{|c|}{ Item } & \multicolumn{1}{c|}{ Explanation } \\
\hline 1 & Supplier power & $\begin{array}{l}\text { An assessment of how easy it is for suppliers to drive up } \\
\text { prices. This is driven by: } \\
\text { the number of suppliers of each essential input } \\
\text { the uniqueness of their product or service } \\
\text { the relative size and strength of the supplier } \\
\text { the cost of switching from one supplier to another. }\end{array}$ \\
\hline 2 & Buyer power & $\begin{array}{l}\text { An assessment of how easy it is for buyers to drive prices } \\
\text { down. This is driven by: } \\
\text { the number of buyers in the market, importance of each } \\
\text { buyer, the cost to the buyer switching from one supplier to } \\
\text { another. A business with a few powerful buyers, are often } \\
\text { able to dictate terms }\end{array}$ \\
\hline 3 & Competitive rivalry & $\begin{array}{l}\text { The key driver is the number and capability of competitors } \\
\text { in the market. Many competitors, offering undifferentiated } \\
\text { products and services, will reduce market attractiveness. }\end{array}$ \\
\hline 4 & Threat of substitution. & $\begin{array}{l}\text { When close substitute products exist in a market the } \\
\text { likelihood of customers switching to alternatives in response } \\
\text { to price increases is high. This reduces both the power of } \\
\text { suppliers and the attractiveness of the market. }\end{array}$ \\
\hline 5 & Threat of new entry. & $\begin{array}{l}\text { Profitable markets attract new entrants, which erodes } \\
\text { profitability. Unless incumbents have strong and durable } \\
\text { barriers to entry, for example, patents, economies of } \\
\text { scale, capital requirements or government policies, then } \\
\text { profitability will decline to a competitive rate }\end{array}$ \\
\hline
\end{tabular}

\section{Four Corner's Analysis}

The four-corner model was developed by Michael Porter as a framework and mechanism for evaluating competition. It is premised on the fact that the major goal of analysing competition should always revolve around gaining insight and projecting into the future.

The model can be useful in the following ways:

- to ascertain profile of possible strategic changes competitors might make and the potential threat they might pose

- evaluate the likely response of each competitor to the different possible strategic action that might be taken by other competitors

- $\quad$ establish the moves and reactions that each competitor will exhibit towards the range of shifts in the industry and environment that may occur.

The 'four corners' involve four diagnostic components that are critical in the analysis of competition: future goals; current strategy; assumptions; and capabilities.

\section{Creating a Strategy Supportive Culture}

According to the configuration of culture and the values which lie at the based of the organisation structure four types of organisational culture can be identified (Oţelea \& Albu, 2008)

1. The role-type culture - The role of coordination is given to a group of people from the management staff. Authority is not based on the skills possessed by the manager but on his status in the chain of command. 


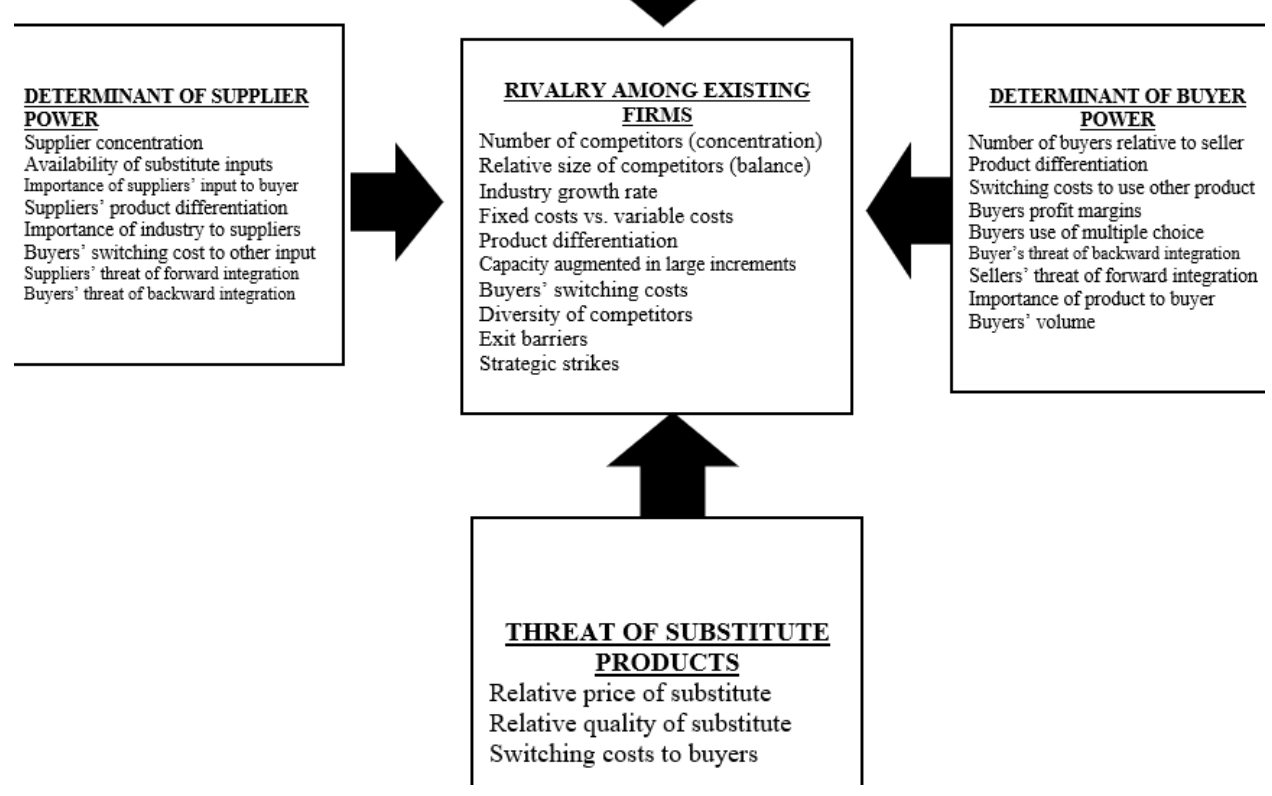

2. The person-type culture - In this type of culture, professionals exemplify the nature of the institution. This contrasts with the traditional types of cultures in which the employee is considered a subordinate and only makes contributions to the actualisation of targeted goals and objectives.

3. The power-type culture- In this case the organisation swiftly responds to the changes that happen within the business environment.

4. The web-type culture -

Culture is considered a major factor that drives strategy (Kazmi, 2002). If the present structure does not support the proposed strategy, then strategist must identify and modify it. It is therefore, imperative that policymakers stress and develop those aspects of existing culture that facilitate the implementation of strategy.

\section{Strategy Implementation}

The implementation of strategy is regarded as one the most difficult and time-consuming aspect of strategy management. This is premised on the fact that formulating a successful strategy does not translate into strategy implementation success. Newman et al, (1989) opined that a huge portion of time of manager is allocated to implementation which requires programming, motivation and controlling. 

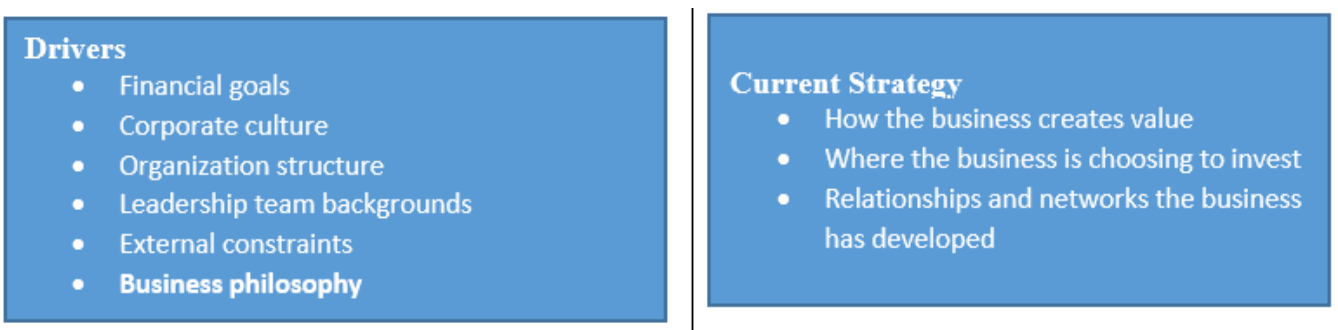

\section{COMPETITORS FUTURE STRATEGY}

\section{Management Assumptions}

- Company's perception of its strengths and weaknesses

- Cultural traits

- Organisational value

- Perceived industry forces

- Belief about competitors' goals

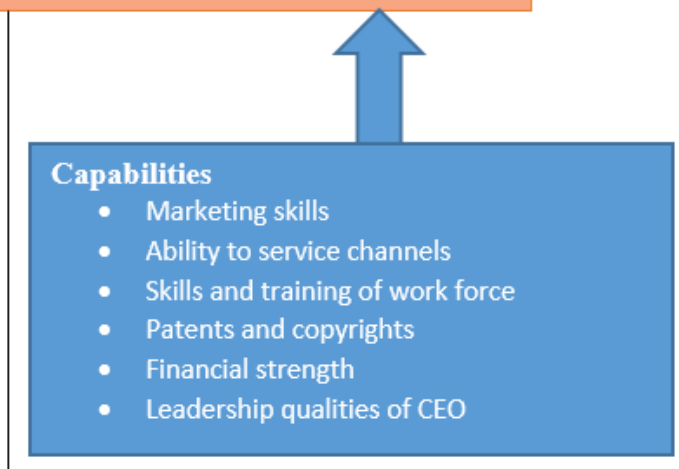

Strategic management process is a full set of commitments, decisions, and actions required for a firm to achieve strategic competitiveness (Hitt et al., 2011) with strategy implementation as a part of the entire process. Strategy implementation, therefore, is the carefully considered processes of ensuring strategies that have been formulated within the organisation are executed to achieve organisational goals and objectives (Ngonze, 2011).

However, as result of the unpredictable nature of any adventure challenges arise during the process strategy implementation. Such challenges fall into two components which are organisational impeders and environmental obstacles. Organisational impeders relate to leadership, systems, policies, resource and capabilities while environment problems deal with issues relating to social, economic, political, donor, and legal issues. (Nour, A.M.,2013).

\section{Non-Governmental Organisations (NGO)}

According to Vakil (1997), NGOs are self-controlling, private, not-for-proðt organisations that are furnished to improve people's quality of life. The term "NGO" is usually synonymous with companies who perform benevolent work in developing countries or across borders. It was coined out during the inauguration of the United Nations in 1945 to refer to non-state entities acting as consultants in UN activities. (Lewis, 2010). 
Over the years, NGO's have operated at local, national and international levels offering humanitarian services. Studies suggest that as at today, a growing number of them are actively engaged in activities geared towards a religious bias; they provide humanitarian services on the platform of faith-based NGOs.

\section{Workplace Relationship}

Workplace relationship is a unique interpersonal relationship which has vital implications for the individuals in the context of the firm.

\section{Superior-Subordinate Relationship}

Although the superior-subordinate relationship may be difficult, it encapsulates many opportunities for both to make the relationship meaningful and fruitful. Organisation consist of different people who congregate to achieve common vision and objective through regulated activities which is the cardinal part of management (Nwachukwu, 1988). Sustaining the relationship between superior and subordinate largely depends on the expectations of the individual parties. Some employee may believe in maintaining close friendship with their boss, others may just be interested in keeping the relationship strictly professional, while those who may not share similar values with their bosses may just give priority to civil relationship.

The relationship between a leader and his subordinates can go a long way to have crucial effect on the performance of the firm. It is important to state here that adopting a democratic style of leadership suggests that subordinates are encouraged to use their initiatives and take responsibility without any form of coercion, which enhances the maximization of subordinate's participation in decision making process. The value of this is that superior - subordinate relationship will drive and instil the sense of value and importance in the subordinates, hence promoting internal cohesion network, satisfying contextual conditions of work and ethics (Sias, 2008). Consequently, this will allow the followers work enthusiastically and make constructive contribution to the success of the organisation.

\section{Historical Development of FBOs in Nigeria}

The evolution of FBOs in Nigeria has remained elusive. However, an attempt is made to highlight the historical progression of the development and establishment of FBOs in Nigeria.

Historically, Churches were the major providers of human development services such as education, healthcare and other social services. This dates to $1842 \mathrm{AD}$ when Christianity arrived.

It vital to state that during the pre-colonial times, before 1861, literatures reviewed fail to provide insights as regard the existence of FBOs of African traditional religion (ATR), as ATR is known to have preceeded Christianity in Nigeria. The Supreme Being and deities were worshipped, and sacrifices offered to them in the belief that these supernatural beings would give the worshippers wealth, happiness and protection, which constitute aspects of human need.

\section{Role of FBOs in Nigeria}

The activities of FBOs cuts across every aspect of life. They range from educational, spiritual, health to social development. Based on inventory taken of past and present times development projects justify this claim. The following according to Baiyeri, 2013), are some of the roles of FBO in Nigeria;

a. Political Development: FBOs have played huge role in advancing the politics in Nigeria.

b. Economic Development: Some of the Economic development programme of many churchowned financial institutions in Nigeria include the CFMB micro finance bank owned by Living Faith Church, Catholic Diocese of Nsukka own by the Kenechukwu Micro Finance Bank. These banks offer loans of various form and offer technical service to their customers. Hence, this support enhances the performance of small and medium scale business activities and be globally 
competitive. The general outcome of their performance is captured in the creation of employment opportunities, wealth creation, cottage industries, farm projects and agro-allied industries.

c. Educational programmes: In terms of educational development, many FBOs in Nigeria have contributed significantly to curriculum reform, building of classroom blocks, skills upgrade for teachers, provision of instructional materials, provision of feeding and boarding system in schools and colleges, and provision of entrepreneurship skill acquisition. Many private universities in Nigeria operate as FBOs namely, Covenant University in Ogun State and Bowen University of the Baptist Conference of Nigeria.

d. Health Care: The delivery of quality healthcare remains a cardinal developmental programme of FBO in Nigeria. For example, the Living Faith Church has established a clinic that provides quality health care in the community. Again, the study of Odumosu, Olaniyi and Alonge (2009) indicated that the Christian Health Association of Nigeria (CHAN) account for over forty percent (40\%) of healthcare services in rural areas of Nigeria.

e. Social Development: Furthermore, social development initiatives which include gender related issues, reproductive and girl-child education, women empowerment has remained a priority developmental programmes of many FBOs in Nigeria. An example is El-Shaddai Widow's Outreach (ELWO) of Suleja, Niger State which aims at promoting the rights of minorities and marginalized population, advocacy, mobilization and creating awareness on health such as HIV/ AIDS, reproductive health, family planning and adolescent health.

\section{PRIMARY RESEARCH}

A variety of sources were used to provide primary data during the research sources from which primary data was gathered are as detailed below:

\section{Questionnaire}

Copies of the questionnaire (Appendices A \& B) was distributed to members of WMA and the staff to fill.

\section{One on One Semi-Structured Interviews}

The interview was conducted with Pastors and members of staff.

Professionals on the subject matter of this study were widely consulted and given access to the measurement tool to provide feedback on the effectiveness of each question in the measurement of the constructs with the goal to ensure content validity (Ghauri \& Gronhaug, 2002; Dawson, 2007). Decisions were based on the feedbacks received.

The structured questionnaire contained several sections that addressed major areas of marketing strategy and loyalty. The author used Five-point Likert scale to design the questionnaire. Personal contact approach was adopted for both distribution and retrieval of the questionnaire. With the support of trained field assistants, copies of the questionnaire was distributed to staff, pastors and members of World Mission Agency in Ota, Ogun State, Nigeria.

The use of semi structured interviews approach allowed for the generation of an in-depth amount of data and insights for the study. The semi-structured interviews were recorded by the researcher.

\section{SECONDARY RESEARCH}

Secondary sources: The secondary source of data was obtained from different literature that was consulted and reviewed. This includes journal articles, text books, internet publications and the operational Manual of WMA (Appendix C). 
Table 2. Reliability of Research Instrument

\begin{tabular}{|c|c|c|c|c|}
\hline $\mathbf{S} / \mathbf{N}$ & Variables & $\begin{array}{l}\text { Number of } \\
\text { items }\end{array}$ & $\begin{array}{l}\text { Reliability Index } \\
\text { by the Author }\end{array}$ & Remark \\
\hline 1 & Mechanic clues & 7 & 0.754 & Reliable \\
\hline 2 & Employees' Personality & 7 & 0.811 & Reliable \\
\hline 3 & Interpersonal Relationship & 5 & 0.765 & Reliable \\
\hline 4 & Organisational social support & 4 & 0.739 & Reliable \\
\hline 5 & Satisfaction & 2 & 0.812 & Reliable \\
\hline \multirow[t]{2}{*}{6} & Loyalty & 4 & 0.784 & Reliable \\
\hline & $\begin{array}{l}\text { Overall Average Alpha for } \\
\text { the instrument }(\alpha)\end{array}$ & 29 & 0.778 & Reliable \\
\hline
\end{tabular}

Source: Researcher's Field Survey, 2018

A total of three hundred and fifty (350) copies of the questionnaire (Appendix A) was distributed to pastors, staff and members of faith based organisation in Ota, Ogun State Nigeria in line with the sample size. Two hundred and ninety-seven (297) copies of the questionnaire was completed and returned by the respondents.

\section{RELIABILITY OF RESEARCH INSTRUMENT}

Reliability refers to the dependability or credibility of the instruments, according to Albert \& O'Connor (2012). The reliability was carried out using the statistical methods such as the Cronbach's alpha and multiple item measures to test the internal consistency of the instruments.

The ANOVA table above explains the statistics of the result and the significance level between the independent and dependent variables. In the ANOVA table, the statistical significance is 0.229. We can statistically accept the alternate hypothesis when P-value is $<0.05$ and reject the hypothesis when it is $>0.05$. This statistically means that we accept the null hypothesis which states that mechanic (ambience) clues has no significant influence on members' satisfaction.

Table 6 shows the extent and contribution of the independent variable mechanic (Ambience) clues to the dependent variable (members' satisfaction). The beta coefficient is 0.199 (19.9\%). This means that a unit change in mechanic (Ambience) clues would result in 19.9\% change in members' satisfaction. This table revealed that the contributions of the mechanic (Ambience) clues (0.229) to the model were insignificant.

Table 3. Effect of Mechanic (Ambience) clues on Members' Satisfaction

\begin{tabular}{|c|c|c|c|c|c|c|}
\hline \multicolumn{7}{|c|}{$A N O V A^{b}$} \\
\hline \multicolumn{2}{|c|}{ Model } & Sum of Squares & Df & Mean Square & $\mathrm{F}$ & Sig. \\
\hline \multirow[t]{3}{*}{1} & Regression & 11.755 & 9 & 1.306 & 1.314 & .229 \\
\hline & Residual & 285.803 & 287 & .994 & & \\
\hline & Total & 297.000 & 296 & & & \\
\hline \multicolumn{7}{|c|}{$\begin{array}{l}\text { a. Predictors: (Constant), Mechanic (Ambience) clues } \\
\text { b. Dependent Variable: Members' Satisfaction } \\
\text { Source: Computed Data (2018) }\end{array}$} \\
\hline
\end{tabular}


Table 4. Multiple Regression result of Combined Effect of mechanic (Ambience) clues components on Members' Satisfaction

\begin{tabular}{|c|c|c|c|c|c|c|}
\hline \multicolumn{7}{|c|}{ Coefficients $^{\mathrm{a}}$} \\
\hline \multirow{2}{*}{\multicolumn{2}{|c|}{ Model }} & \multicolumn{2}{|c|}{ Standardized Coefficients } & \multirow{3}{*}{$\begin{array}{c}\text { df } \\
\\
1\end{array}$} & \multirow{3}{*}{$\begin{array}{c}\mathbf{F} \\
.923\end{array}$} & \multirow{3}{*}{$\begin{array}{l}\text { Sig. } \\
.338\end{array}$} \\
\hline & & \multirow{2}{*}{\begin{tabular}{r|} 
Beta \\
-.108
\end{tabular}} & \multirow{2}{*}{$\begin{array}{c}\begin{array}{c}\text { Bootstrap } \\
\text { (1000) Estimate } \\
\text { of Std. Error }\end{array} \\
.113\end{array}$} & & & \\
\hline 1 & Mechanic (Ambiance) Clues1 & & & & & \\
\hline & Mechanic (Ambiance) Clues2 & -.027 & .124 & 1 & .046 & .830 \\
\hline & Mechanic (Ambiance) Clues3 & -.067 & .094 & 1 & .501 & .479 \\
\hline & Mechanic (Ambiance) Clues4 & -.082 & .127 & 1 & .413 & .521 \\
\hline & Mechanic (Ambiance) Clues5 & .069 & .231 & 1 & .089 & .766 \\
\hline & Mechanic (Ambiance) Clues6 & -.143 & .219 & 2 & .425 & .654 \\
\hline & Mechanic (Ambiance) Clues7 & .050 & .221 & 2 & .050 & .951 \\
\hline
\end{tabular}

Significant at less than $0.05\left({ }^{* *}\right)$

Source: Computed Data (2018)

Decision: Hence, the null hypothesis $\left(\mathrm{H}_{0}\right)$ was accepted while the alternate hypothesis $\left(\mathrm{H}_{1}\right)$ rejected. By implication, mechanic (ambience) clues explains $4 \%$ variance in model but have no significant effect on members' satisfaction.

Objective 2: To analyse the effect of organisational social supports on members'

The results from Table 6.15(a) explains the extent of variance to which the dependent (members' satisfaction) variable is explained by the independent variable using the co-efficient determination $\left(r^{2}\right)$ of $6 \%(\mathrm{R}$ square $=0.060)$. This implies that $94 \%$ variance was not accounted for in this study i.e. not only organisational social support contributes to members' satisfaction and hence, other variables make up the remaining $94 \%$.

Table 6.16(c) ascertained the strength of association between the independent variable organisational social supports and the dependent variable (members' satisfaction). The table revealed that interpersonal relationship (0.022) made significant contributions to the model except for IR4 that was insignificant. The result shows that for one-unit change in organisational social supports, members' satisfaction will increase by $24.4 \%$.

Decision: Hence, the null hypothesis $\left(\mathrm{H}_{0}\right)$ was rejected while the alternate hypothesis $\left(\mathrm{H}_{1}\right)$ accepted. By implication, organisational social supports have significant effect on members' satisfaction.

Table 5. Effect of Organisational Social Supports on Members' Satisfaction

\begin{tabular}{|c|c|c|c|c|}
\hline \multicolumn{7}{|c|}{ Model Summary } \\
\hline Model & Multiple R & R Square & Adjusted R Square & Apparent Prediction Error \\
\hline 1 & .244 & .060 & .034 & .940 \\
\hline \multicolumn{5}{|c|}{ Predictors: (Constant), Organisational Social Supports } \\
Source: Computed Data (2018) \\
\hline
\end{tabular}


Table 6. Multiple Regression result of Combined Effect of Organisational Social Supports on members' satisfaction

\begin{tabular}{|c|c|c|c|c|c|}
\hline \multicolumn{2}{|c|}{ Coefficients $^{\text {a }}$} \\
\hline \multirow{2}{*}{ Model } & Standardized Coefficients & df & \multicolumn{2}{|c|}{ F } & Sig. \\
\cline { 2 - 6 } & Beta & $\begin{array}{c}\text { Bootstrap (1000) } \\
\text { Estimate of Std. } \\
\text { Error }\end{array}$ & & & \\
\hline Organisational Social Support1 & .187 & .141 & 2 & .381 & $.004^{* *}$ \\
\hline Organisational Social Support2 & .161 & .132 & 2 & .216 & $.006^{* *}$ \\
\hline Organisational Social Support3 & .216 & .145 & 3 & 2.211 & $.037^{* *}$ \\
\hline Organisational Social Support4 & .034 & .106 & 1 & .102 & .750 \\
\hline
\end{tabular}

Source: Computed Data (2018)

${ }^{*}$ Value is significant when it is less than 0.05

\section{Interpretation of The Model}

The model explains the degree of association between/among existing constructs. Using the two-step approach, the research model and hypotheses were tested by using the structural equation modelling (SEM) techniques. The results of SEM analysis are reported in Fig. 1. Because this study regards that four antecedent variables (i.e. corporate culture) are independent, 5 pair-wise relationships are set to zero in AMOS program. Besides, we also set two dependent variables correlated in AMOS program due to theoretical viewpoint that mechanic (Ambience) clues and satisfaction are not of causality but related. Then the structural model is tested after these constrains. The result indicate that all the basic assumptions were acceptable and prove that the data met the conditions of basic assumption in regression analysis $(\mathrm{CFI}=0.930, \mathrm{GFI}=0.912, \mathrm{RMSEA}=0.048$, and CMIN/DF $=2.352)$.

Each research hypothesis is tested by examining the path coefficients and its level of significance. $\mathrm{H} 1 \mathrm{a}$ is supported that the path coefficients are $\gamma=.924(\mathrm{t}=41.587, \mathrm{p}<0.01) . \mathrm{H} 2 \mathrm{a}$ is supported that the path coefficient is $\gamma=0.560(\mathrm{t}=11.624, \mathrm{p}<0.001)$. H3a is supported that the path coefficient is $\gamma=0.938$

Figure 3.

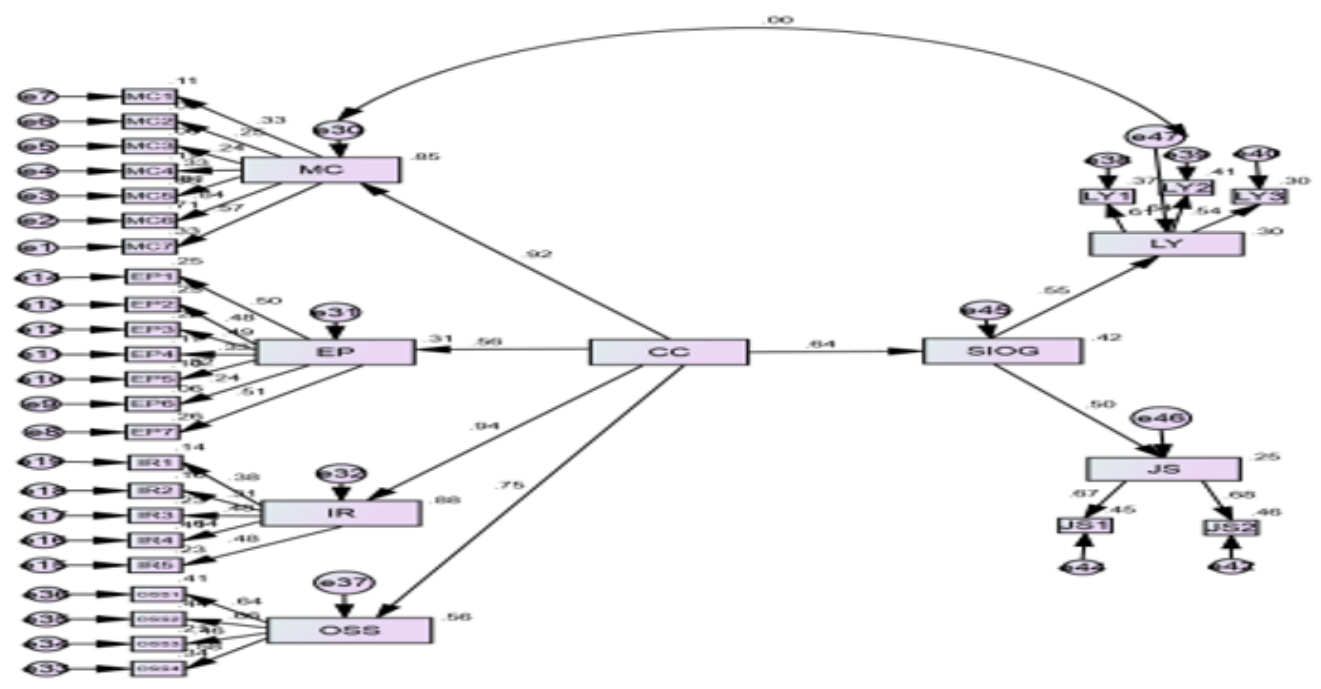


Table 7. Regression Weights of the Variables

\begin{tabular}{|c|c|c|c|c|c|c|c|}
\hline DV & & IV & Estimate & S.E. & T $_{\text {value }}$ & P & Sig \\
\hline SIOG & $\begin{array}{c}<- \\
--\end{array}$ & CC & .644 & .033 & 14.498 & $* * *$ & Sig \\
\hline MC & $\begin{array}{c}<- \\
--\end{array}$ & CC & .924 & .033 & 41.587 & $* * *$ & Sig \\
\hline $\begin{array}{c}<- \\
--\end{array}$ & CC & .938 & .026 & 46.463 & $* * *$ & Sig \\
\hline IR & $\begin{array}{c}<- \\
-\end{array}$ & CC & .750 & .057 & 19.518 & $* * *$ & Sig \\
\hline EP & $\begin{array}{c}<- \\
--\end{array}$ & CC & .560 & .039 & 11.624 & $* * *$ & Sig \\
\hline LY & $\begin{array}{l}<- \\
--\end{array}$ & SIOG & .550 & .055 & 11.336 & $* * *$ & Sig \\
\hline JS & $\begin{array}{c}<- \\
--\end{array}$ & SIOG & .495 & .066 & 9.803 & $* * *$ & Sig \\
\hline
\end{tabular}

Table 8. The Model Fit Summary Showing the Goodness of Fitness

\begin{tabular}{|c|c|c|c|}
\hline Goodness of fit & SEMs Value & $\begin{array}{c}\text { Recommendation } \\
\text { Values }\end{array}$ & Remarks \\
\hline $\begin{array}{c}\text { ChiSquare/Degree of Freedom (CMIN/ } \\
\text { DF) }\end{array}$ & 2.352 & $\leq 3.00$ & Acceptable fit \\
\hline Normed Fit Index (NFI) & 0.972 & $\geq .90$ & Good fit \\
\hline Comparative Fit Index (CFI) & 0.930 & $\geq .90$ & Good fit \\
\hline Incremental Fit Index (IFI) & 0.951 & $\leq .90$ & Good fit \\
\hline $\begin{array}{c}\text { Root Mean Squared Error of } \\
\text { Approximation (RMSEA) }\end{array}$ & .048 & $\geq .90$ & Good fit \\
\hline Goodness of Fit (GFI) & .912 & & $\geq 08$ \\
\hline
\end{tabular}

$(\mathrm{t}=46.463, \mathrm{p}<0.001) . \mathrm{H} 4 \mathrm{a}$ is supported that the path coefficients are $\gamma=0.750(\mathrm{t}=19.518, \mathrm{p}<0.01)$. Other details on the items for each construct are shown in Figure 6.1 and table 6.14 respectively.

In conclusion, structural equation model technique can estimate several multiple regression equations at a time whereby more than one dependent variable can be tested. In our model, we posit corporate culture and strategic implementation of organisational growth is correlated. It was observed that the relationship between all the variables are significant and positive with interpersonal relationship and Mechanic clues having the highest value while employee personality had the least value.

\section{DISCUSSION AND CONCLUSIONS}

In recent times the existence of NGOs has increased in number and impact. The result of this is the enhancement of human dignity. Many faith-based with a strong spiritual thrust as well as social impact. The purpose of this research is to investigate the impact of faith-based organisations and how this can be enhanced strong corporate strategy using WMA as a case study. 
Faith-based organisations have dominated every aspect of our lives. Furthermore, most have underscored the importance of social and economic impact as critical tenets of their faith. To this end, faith-based organisations have a significant role to play in driving social and economic impact in nations all over the world.

This study indicates that faith based organisation can re-invent their present strategies to maximise performance in the following ways:

1. By continually providing adequate physical aesthetics, furniture and fittings to enhance members' engagement level;

2. By ensuring and maintaining courteous relationships with all its members;

3. By encouraging group members to share ideas and opinions from time to time and confide in each other on life related problems e.g. work, family, finances for encouragement and edification;

4. By ensuring that members are continually satisfied with the overall welfare service offered by the organisation and consequently strengthen the social support systems.

This study concluded that physical aesthetics, furniture and fittings of the organisation has significant impact on the satisfaction of members. In other words, the results indicate that physical ambiance of the organisation has a very strong influence on member's satisfaction.

In addition, this study concluded that social support is impactful. However, areas such as the provision of soft loans for small businesses, financial literacy and platforms for digital interactions may be required to encourage knowledge sharing and building trustworthiness amongst people.

From the aforementioned WMA's culture can be said to be embodied in their corporate strategy.

\section{RECOMMENDATIONS}

Based on the findings of this research, the following recommendations were made:

Faith-based organisations should pay close attention to members' satisfaction. This must constitute a guiding principle that drives the thinking, behaviour and philosophy of the organisations.

Faith-based organisations should intentionally facilitate memorable members' experience, which begins by concentrating on physical aesthetics such as furniture, fittings and physical ambiance of the organisation to attract members and increase members' engagement level. In other words, the environment must always be conducive.

This study recommends that faith-based organisations need to continually ensure that they consistently provide training for employees and develop their capacity to handle people. Employees must be able to accommodate people irrespective of their peculiarities; who they are and where they come from. This is important as it will provide a favourable and lasting impression in the mind of members.

In relation to social support, this study recommends that there is need for more emphasis to be placed on the following highlighted area:

a. Financial literacy programmes;

b. Granting of soft loans for small scale businesses with provision of ensuring accountability and judicious use of funds given;

c. Entrepreneurship should be encouraged and taught;

d. Creating platforms for digital interactions to encourage knowledge sharing and building trustworthy relationships is to be considered as part of essentials for alleviating poverty and hardship especially in nations where such conditions are prevalent. 


\section{REFERENCES}

Baiyeri, H. B. (2013). The role of Faith-based organizations (FBOs) in Human Development: A study of Kogi State (Doctoral dissertation). Faculty of the Social Science University of Nigeria Nsukka. Available from http:// www. unn. edu.ng/publications/files/BAIYERI,\%20H.\%20B.pdf

Baumgartner, R. J., \& Korhonen, J. (2010). Strategic thinking for sustainable development. Sustainable Development, 18(2), 71-75. doi:10.1002/sd.452

Berry, J. W., Phinney, J. S., Sam, D. L., \& Vedder, P. (2006). Immigrant youth: Acculturation, identity, and adaptation. Applied Psychology, 55(3), 303-332. doi:10.1111/j.1464-0597.2006.00256.x

Berry, J. W., Phinney, J. S., Sam, D. L., \& Vedder, P. (2006). Immigrant youth: Acculturation, identity, and adaptation. Applied Psychology, 55(3), 303-332. doi:10.1111/j.1464-0597.2006.00256.x

Bitner, M. J. (1992). Servicescapes: The impact of physical surroundings on customers and employees. Journal of Marketing, 56(2), 57-71. doi:10.1177/002224299205600205

Ellison, C. G., \& George, L. K. (1994). Religious involvement, social ties, and social support in a southeastern community. Journal for the Scientific Study of Religion, 33(1), 46-61. doi:10.2307/1386636

George, L. K., Ellison, C. G., \& Larson, D. (2002). Explaining the relationships between religious involvement and health. Psychological Inquiry, 13(3), 190-200. doi:10.1207/S15327965PLI1303_04

Greenland, S. J., \& McGoldrick, P. J. (1994). Atmospherics, attitudes and behaviour: Modelling the impact of designed space. International Review of Retail, Distribution and Consumer Research, 4(1), 1-16. doi:10.1080/09593969400000001

Haeckel, S. H., Carbone, L. P., \& Berry, L. L. (2003). How to lead the customer experience. Marketing Management, 12(1), 18-18.

Hitt, M. A., Ireland, R. D., Sirmon, D. G., \& Trahms, C. A. (2011). Strategic entrepreneurship: Creating value for individuals, organizations, and society. The Academy of Management Perspectives, 25(2), 57-75.

Inegbedion, H. E. (2018). Factors that influence customers' attitude toward electronic banking in Nigeria. Journal of Internet Commerce, 17(4), 325-338. doi:10.1080/15332861.2018.1463482

Kim, P. Y. (2017). Religious support mediates the racial microaggressions-mental health relation among Christian ethnic minority students. Psychology of Religion and Spirituality, 9(2), 148-157. doi:10.1037/rel0000076

Kramer, F. D. (2010). The role for public funding of faith-based organizations delivering behavioral health services: Guideposts for monitoring and evaluation. American Journal of Community Psychology, 46(3-4), 342-360. doi:10.1007/s10464-010-9351-8

Krause, N., \& Hayward, R. D. (2012). Religion, meaning in life, and change in physical functioning during late adulthood. Journal of Adult Development, 19(3), 158-16. doi:10.1007/s10804-012-9143-5

Lewis, R. (2010). When cultures collide. Nicholas Brealey Publishing.

Mbithe, N. P. (2011). Factors Influencing Strategy Implementation at the Co-operative Bank of Kenya.

Nagel, E., \& Sgoutas-Emch, S. (2007). The relationship between spirituality, health beliefs, and health behaviors in college students. Journal of Religion and Health, 46(1), 141-154. doi:10.1007/s10943-006-9088-8

Nour, A. M. (2013). Challenges of strategy implementation faced by international NGOs in Somaliland (Unpublished MBA project). University of Nairobi.

Olokundun, M. A., Olaleke, O., Peter, F., Ibidunni, A. S., \& Amaihian, A. B. (2017). Examining the link between university support systems, knowledge sharing and innovation: A focus on Nigerian university students. Journal of Entrepreneurship Education, 20(2), 1-9.

Olson, P. D., \& Bokor, D. W. (1995). Strategy process-content interaction: Effects on growth perf. Journal of Small Business Management, 33(1), 34. 
Omar, A. T., Leach, D., \& March, J. (2014). Collaboration between nonprofit and business sectors: A framework to guide strategy development for nonprofit organizations. Voluntas, 25(3), 657-678. doi:10.1007/s11266-0139357-6

Preble, J. F. (1992). Towards a comprehensive system of strategic control. Journal of Management Studies, 29(4), 391-408. doi:10.1111/j.1467-6486.1992.tb00671.x

Sharma, A., \& Stafford, T. F. (2000). The Effect of Retail Atmospherics on Customers' Perceptions of Salespeople and Customer Persuasion: An Empirical Investigation. Journal of Business Research, 49(2), 183-191. doi:10.1016/ S0148-2963(99)00004-1

Sunday, C. E., \& Vera, C. C. E. (2018). Examining information and communication technology (ICT) adoption in SMEs: A dynamic capabilities approach. Journal of Enterprise Information Management, 31(2), 338-356. doi:10.1108/JEIM-12-2014-0125

Weisbrod, B. A. (1998). The nonprofit mission and its financing: Growing links between nonprofits and the rest of the economy. To profit or not to profit: The commercial transformation of the nonprofit sector, 1-22.

Yanney, J. P., Dennis, K. A., \& Awuah, G. K. (2015). The Effect of Business Strategy on Organizational Performance of Small-Medium Scale Enterprises in the Manufacturing Sector of Ghana. GRIN Verlag. 